\title{
NEW TRENDS IN THE PREVENTION OF OCCUPATIONAL NOISE-INDUCED HEARING LOSS
}

\author{
MARIOLA SLIWINSKA-KOWALSKA \\ Nofer Institute of Occupational Medicine, Łódź, Poland \\ Department of Audiology and Phoniatrics
}

\begin{abstract}
Noise exposure during lifespan is one of the main causes of hearing loss. The highest risk of noise-induced hearing loss (NIHL) is related to exposures in the workplace, and affects about $7 \%$ of the population. Occupational NIHL is irreversible, thus its prevention must be considered a priority. Although current hearing conservation programs (HCPs) have proved to be very beneficial, the incidence of occupational NIHL is still high, reaching about $18 \%$ of overexposed workers. This paper reviews recent research on the effects of noise on hearing in pursuit of more effective methods for the prevention of occupational NIHL. The paper discusses the translational significance of noise-induced cochlear neuropathy, as recently shown in animals, and the concept of hidden hearing loss in relation to current NIHL damage risk criteria. The anticipated advantages of monitoring the incidents of the temporary threshold shift (TTS) in workers exposed to high levels of noise have been analyzed in regard to the preclinical diagnostics of NIHL, i.e., at the stage when hearing loss is still reversible. The challenges, such as introducing speech-in-noise audiometry and TTS computational predictive models into HCPs, have been discussed. Finally, the paper underscores the need to develop personalized medical guidelines for the prevention of NIHL and to account for several NIHL risk factors other than these included in the ISO 1999:2013 model. Implementing the steps mentioned above would presumably further reduce the incidence of occupational NIHL, as well as associated social costs. Int J Occup Med Environ Health. 2020;33(6):841-8
\end{abstract}

Key words:

predictive models, cochlear neuropathy, temporary threshold shift, individual susceptibility to noise, speech in noise, medical guidelines

\section{INTRODUCTION}

Noise exposure is common in today's world and, if excessive, may result in deteriorative auditory and non-auditory effects, promoting a subject's isolation and dementia. In particular, prolonged overexposures to noise can result in noise-induced hearing loss (NIHL) and noise-induced tinnitus. While NIHL is an irreversible form of hearing loss, it can be effectively prevented.

The highest risk for hearing damage due to exposure to noise in the USA was observed in the mining and wood products industry $(27 \%)$, followed by building and real estate construction (23.5\%), and the agriculture, forestry, fishing and hunting sectors (15\%) [1]. Among workers exposed to noise, approx. $33 \%$ exhibit audiometric evidence of noise-induced hearing damage, while $16 \%$ have material hearing impairment [2]. Different sources of noise are present in the military environment, varying from impulse (weapon systems) to continuous types (jet, vehicles, bootengines, etc.) [3]. Entertainment and music industry employees constitute a separate category of exposed workers $[4,5]$.

\footnotetext{
Funding: this study was supported in part by the European Commission Horizon 2020 Research and Innovation program (project No H2020-SCI-2016-CNECT, project No 727521, entitled "Evidence-based management of hearing impairment. Public health policy making based on fusing big data analytics and simulation," project manager: OTICON A/S, Denmark).

Received: January 20, 2020. Accepted: June 17, 2020.

Corresponding author: Mariola Sliwinska-Kowalska, Nofer Institute of Occupational Medicine, Department of Audiology and Phoniatrics, św. Teresy 8, 91-348 Łódź, Poland (e-mail: mariola.sliwinska@imp.lodz.pl).
} 
Daily noise exposure $\left(\mathrm{L}_{\mathrm{EX}, \mathrm{Bh}}\right)$ in nightclubs and pubs was estimated at 92-95 dB(A), i.e., approx. 4 times higher than the legally accepted limits [5]. Since the majority of these subjects do not use hearing protection, their risk of developing NIHL is very high.

Since NIHL is an irreversible condition, its prevention is considered a priority. Occupational hearing loss is preventable through the use of engineering and administrative controls, hearing protection devices, and the monitoring of hearing with audiometric testing. Long-lasting beneficial effects of the currently functioning hearing conservation programs (HCPs) in developed countries have been lately documented with longitudinal studies of workers exposed to occupational and military noise $[3,6]$. However, the incidence of occupational NIHL is still high, placing this disease among the most common occupational disabilities worldwide.

Currently, regular annual audiometric testing under HCPs is mandatory to all workers exposed to occupational noise which exceeds permissible levels. Pure-tone audiometry allows detecting the first signs of NIHL, i.e., notched audiograms at high frequencies of $3000 \mathrm{~Hz}, 4000 \mathrm{~Hz}$ and $6000 \mathrm{~Hz}$, and is used in the monitoring of hearing over one's professional career. However, annual audiograms identify permanent changes in hearing, i.e., at the stage when hearing loss is already irreversible.

So far, there has been no suitable hearing testing method for monitoring NIHL at the "preclinical" stage, i.e., before the permanent threshold shift (PTS) occurs. Otoacoustic emissions (OAEs) were believed to be a promising solution in the 1990s and 2000s. However, more recent results of longitudinal studies have shown that OAEs do not provide higher sensitivity in assessing hearing damage related to prolonged exposure to noise than pure-tone audiometry [7].

The monitoring of temporary threshold shift (TTS) incidents after exposure to noise is an alternative and quite promising approach to the prevention of permanent hear- ing loss. Although this concept is not new, it has lately gained relevance in the light of animal studies indicating that exposure to moderate noise which results in TTS may lead to irreversible progressive neural damage of the auditory organ.

This paper is an overview of the latest research published on the effects of noise on hearing in pursuit of more effective methods for the medical prevention of occupational NIHL. The other goal of this study is to demonstrate the need to personalize the medical guidelines for the prevention of NIHL, taking into account individual factors determining susceptibility to noise.

\section{COCHLEAR SYNAPTOPATHY \\ AND NEURAL DAMAGE INDUCED BY MODERATE EXPOSURE TO NOISE}

Noise-induced hearing loss is sensorineural in origin and develops slowly over the years of exposure. Although the outer hair cells (OHCs) of the organ of Corti are believed to be the primary site of such lesions, recent animal studies have shown that moderate noise exposure resulting in TTS can also trigger a substantial and irreversible degeneration of auditory fibers without affecting OHCs and absolute hearing sensitivity permanently. Despite the lack of any permanent hair cell loss and recovery of threshold sensitivity, exposed animals demonstrate extensive loss of synaptic connections between cochlear inner hair cells and auditory nerve terminals [8]. The loss of synapses is then followed by the degeneration of the spiral ganglion cells and auditory nerve fibers, which can occur months to years after the damage to the synapses. Such a condition continues even if noise exposure is discontinued and hearing thresholds return to normal. This phenomenon has been commonly named hidden hearing loss (HHL) [9]. Therefore, animal data indicates that noise exposure without PTS predisposes the auditory system to premature neural ageing [10]. Noise-induced cochlear synaptopathy followed by neural degeneration is selective for high-threshold auditory 
nerve fibers with low spontaneous rates (low-SRs) [11]. In humans, low-SR auditory fibers are important for processing suprathreshold sounds and their damage may have a particularly adverse effect on understanding speech in the presence of background noise.

As many as $5-15 \%$ of adult patients seeking audiologic help have normal hearing thresholds [12], and thus cochlear synaptopathy may be the cause of their hearing complaints. In addition, older adults with mild-to-moderate age-related hearing loss may additionally display neural dysfunction, which partially contributes to their difficulties in communicating and to the limited benefit they experience using hearing aids (HAs). If cochlear synaptopathy is observed in human subjects, millions of people in Europe and around the world are at risk of developing hearing difficulties that will ultimately affect their quality of life and level of social participation.

A number of cross-sectional studies have examined the noise-induced HHL phenomenon in humans. Thus far, their results are inconclusive [13-16]. In the study by Liberman et al. [13], 34 young college students with normal hearing were divided into high risk and low risk groups based on self-reported exposure to noise and the use of hearing protection. Cochlear function was assessed by OAEs and click-evoked electrocochleography (ECoG); hearing was assessed by behavioral audiometry and word recognition with or without noise (or with time compression and reverberation). The ratio of the summating potential to the action potential (the SP/AP ratio) and speech recognition in noise (or with time compression and reverberation) were the 2 promising non-behavioral measures for cochlear synaptopathy in this study [13]. This observation is in line with the findings by Valderrama et al. [14]. The authors showed a negative correlation between wave I amplitude of the auditory brainstem responses (ABR) and the lifetime exposure to noise in a large cohort of adults aged 29-55. However, large intersubject variability was observed in this investigation.
Opposite conclusions were reached in the largest up-to-date study performed by Prendergast et al. [15] in 126 young humans with normal audiometric thresholds. Contrary to the assumptions drawn from the animal models, no relation was found between exposure to noise and wave I amplitude of ABR with the use of high-level stimuli [15]. Moreover, when extending this cohort by additional 33 older adults, the same group of authors showed that age and noise exposure were the only significant predictors of performance in speech in noise testing (the digit triplet test), while ABR and other electrophysiological tests measures were not [16]. It seems that the major methodological constraint for proving the HHL phenomenon in humans is a lack of reliable procedures to test inner hair cells and their ribbon synapses in vivo. An alternative explanation of the discrepancies between the studies is that the functional defect caused by noise-induced cochlear synaptopathy in human subjects is smaller than it could be anticipated based on animal research results.

Confirming the findings obtained in animals in human subjects would significantly influence the approach to HCPs in workers exposed to noise, and would have an impact on the medicolegal aspects of occupational hearing loss compensation. It should be presumed that even incidental and moderate exposures to noise may cause long-lasting hearing effects, along with the development of premature presbycusis. Since TTS incidents can be observed for incidents with A-weighted equivalent-continuous sound pressure levels of $>78 \mathrm{dBA}$ for longer periods (up to $16 \mathrm{~h} /$ day), the size of the population at danger could be significantly larger than previously assumed, comprising also those exposed to environmental and entertainment/pleasure noises.

\section{PREVENTION OF OCCUPATIONAL NIHL BY MONITORING TTS INCIDENTS?}

Hearing loss after a short exposure to intense noise (e.g., after a work shift) is occasionally temporary and can be documented as TTS. Due to the repeated chronic 
noise exposure, hearing loss may become permanent. The mechanisms of TTS and PTS are different. Generally, TTS develops when the metabolic capacity of the sensory cells of the organ of Corti is exhausted and OHCs stereocilia become uncoupled from the tectorial membrane. On the other hand, PTS takes place as a consequence of the death of hair cells followed by degeneration of some afferent nerve fibers [17].

In some countries in the 1970s and 1980s, TTS testing was performed in workers prior to their commencement of employment involving exposure to noise. It was speculated that the 4-kHz magnitude of an audiometric notch after acute exposure to noise may predict workers' susceptibility to NIHL. A TTS value of $40 \mathrm{~dB}$ occurring 2 min after exposure to broadband noise of low frequencies, at the level of $100 \mathrm{dBA}$ for $20 \mathrm{~min}$, was considered pathological and believed to promote PTS [18]. Comparing the TTS measurements with PTS values recorded for the same employees years after the initial acute exposure did not preclude this possibility [19]. In the study by Moshammer et al. [19], > 300 fitters and welders of steel division were monitored with pure-tone audiometry, on average for 13 years. All subjects demonstrated normal hearing at their initial health screening, during which a standardized exposure to noise was applied and TTS was measured 10 min later. The results of this study showed a good prediction of PTS based on the TTS value. Even though the publication by Moshammer et al. was criticized for methodological flaws, the results of studies on cochlear neuropathy in animals prompt the question whether regular TTS testing (e.g., after a work shift) could have any added value in currently conducted HCPs [19].

More recently, an attempt to assess the relationship between subjective reports of TTS incidents and the prevalence of hearing problems has been undertaken by Brungart et al. [20] in military personnel. Results of the survey obtained from 3330 U.S. service members indicated that reports of TTS were substantially more predictive of hearing complaints than questions regarding exposure to noise [20]. However, so far there are no longitudinal studies monitoring TTS incidents with audiometric testing in workers exposed to occupational noise.

To date, several approaches have been proposed to increase the effectiveness of HCPs and to decrease the burden related to occupational NIHL. Most intervention programs are based on education activities designed to increase the subjects' awareness of noise-related health effects and their hearing self-protection. Both the individual-tailored strategy and the untailored strategy have been used, but neither of them has shown to be efficient over an extended period [21]. Providing workers with the possibility of realtime self-control measurement of daily noise exposure has shown to be much more effective. This approach translates to a higher motivation of workers to closely follow the operational manuals of hearing protectors when the levels of noise exceed allowable values. A randomized study using self-control individual dosimetry showed that the percentage of subjects exposed to noise at levels of $>85 \mathrm{~dB}(\mathrm{~A})$ significantly decreased [22].

A similar beneficial effect could be expected using TTS monitoring. Introducing TTS measurements to HCPs in occupational settings would allow a self-controlled monitoring of changes in hearing, increasing workers' awareness and providing individuals with direct evidence of hearing protectors' efficiency. As a result, this method would motivate workers to use hearing protection if TTS appears. Monitoring TTS incidents would also allow an early pharmacological intervention, if necessary.

Given the digitalization and technological advances, computerized TTS prediction models could be used to reduce the costs of testing the actual TTS values at workplaces. Computational TTS models were first described in the late 1970s [23], and then validated in the 1990s for people with normal hearing [24], as well as in hearing-impaired subjects [25]. An improved model for predicting TTS episodes at $4 \mathrm{kHz}$ has been recently developed for individuals with hearing loss wearing HAs under the "EVOTION" project 
(Evidence-based management of hearing. Public health policy making based on fusing big data analytics and simulation - H2020-SCI-2016-CNECT, project No. 727521), supported by European funds under the Horizon 2020 program [26]. The model takes into consideration the HA device as an additional sound source which has an impact on the level of TTS, and thus affects the identification of TTS episodes. The improved TTS predictive model supplemented with data about a specific person can be applied to individual cases. The method could then encompass all workers, including those using HAs or cochlear implants. One of the early signs of ageing of the auditory organ is an impaired understanding of speech in noisy environments, which can also be reported by subjects with otherwise "normal" hearing [27]. Recently, the influence of exposure to high levels of sounds on speech in noise recognition has been assessed in music college students with normal hearing. The authors showed that greater routine noise exposure predicted worse quick-speech-in-noise test scores, and they concluded that noise exposure might diminish a musician's advantage for perceiving speech in noise [28].

Further studies are needed to assess whether speech-innoise testing may become a more sensitive and suitable method in the "preclinical" monitoring of NIHL than pure-tone audiometry. Music and entertainment industry employees constitute a model population for investigation, since they regularly experience excessive noise levels and repeated TTS episodes, working without hearing protection [5]. Longitudinal studies monitoring hearing loss after exposure to occupational noise, with the use of speech-in-noise tests, could be also beneficial to verify whether the HHL concept is applicable to humans.

\section{PERSONALIZED MEDICAL GUIDELINES FOR THE PREVENTION OF NIHL}

Currently, NIHL risk assessment is performed using the ISO 1999:2013 model, which includes the following 4 population variables: age, gender, the level of exposure to noise, and the time of exposure to noise in years [29]. However, the ISO model shows very substantial differences in PTS prediction - reaching up to a $60 \mathrm{~dB}$ HL difference between persons most sensitive and most resistant to noise. This variability is attributed to several factors other than these included in the ISO model, such as coexposure to ototoxic substances (organic solvents, ototoxic drugs), heredity (gene polymorphisms), and several determinants of individual susceptibility to noise, such as an increased level of lipids, metabolic diseases (diabetes), hypertension, as well as habits (cigarette smoking) [30]. The results of recent systematic review papers call for an urgent implementation of hearing protection standards for workers exposed to organic solvents, such as styrene, toluene and mixtures of solvents, particularly in the case of combined exposures to these chemicals and noise [31,32]. As a consequence of studies on organic solvents, the updated European Directive 2003/10/EC [33] stipulates that employers should estimate the risk of hearing impairment due to exposure to organic solvents in co-exposure with noise. Nonetheless, in practice, there are no tools available to implement this provision into hearing protection programs.

The challenge today is to develop quantitative models for estimating an individual risk of NIHL, thus allowing to introduce the rules of personalized (precise) medicine standards into HCPs. An individual hearing impairment risk assessment model proposed by this group would be an incremental step towards this goal [34]. Apart from the 4 ISO variables, the model accounts for factors such as cigarette smoking, co-exposure to organic solvents, hypertension and using hearing protection.

However, even the current state of knowledge is sufficient to develop personalized medical guidelines for the prevention of NIHL. One example would be to establish a guideline on protecting workers' hearing in the case of exposure to organic solvents, and co-exposure to noise and solvents. Current studies indicate the necessity to perform annual audiometric 
testing in all workers exposed to organic solvents whose concentration in the air exceeds permissible values. As regards workers exposed to noise and organic solvents, audiometric examinations should be mandatory in all subjects in whom the level of noise exceeds the lower action level defined by Directive 2003/10/EC, i.e., $\mathrm{L}_{\mathrm{EX}, 8 \mathrm{~h}}=80 \mathrm{~dB}$ [35]. Since it has been shown that organic solvents damage both the peripheral and the central part of the hearing system, apart from pure-tone audiometry, diagnostics must also encompass suprathreshold auditory processing tests [36]. Speech-innoise audiometry could again be the method of choice in this regard.

Regarding individual health factors, such as hypertension, diabetes or obesity, the course of action is to conduct informational campaigns among physicians and medical personnel. Concurrently, appropriate medical guidelines should be developed, in order to specify the hearing monitoring methods in employees subject to these factors; they should also include the scope and frequency of prophylactic assessments.

\section{CONCLUSIONS}

In conclusion, recent research conducted in animals and humans has constituted a new challenge for a better prevention of occupational NIHL. While animal model tests on cochlear neuropathy and HHL do not provide the basis for re-examination of the current NIHL damage criteria, they are a stimulus to initiate longitudinal studies on the temporary changes in hearing which occur in humans after noise exposure, preferably with the use of speech-in-noise audiometry. These studies would be relevant as basic research to explore the HHL mechanism in humans, and perhaps - have practical significance in the monitoring of reversible stages of NIHL in the future.

Substantial progress in the prevention of NIHL would be achieved through the verification of medical guidelines used in HCPs, and their adjustment to co-exposures in occupational settings, individual susceptibility factors and specific needs of given workers. Digitalization and technical advancements should contribute to the development of advanced methods and tools for the improved personalized prevention of hearing loss, and an increased accessibility of this protection in workers' everyday practice, and, therefore, to reducing the incidence of occupational NIHL and associated social costs.

\section{REFERENCES}

1. Materson EA, Tak S, Themann CL, Wall DK, Groenewold MR, Deddens JA, et al. Prevalence of hearing loss in the United States by industry. Am J Ind Med. 2013;56(6):67081, https://doi.org/10.1002/ajim.22082.

2. Themann CL, Masterson EA. Occupational noise exposure: A review of its effects, epidemiology, and impact with recommendations for reducing its burden. J Acoust Soc Am. 2019;146(5):3879, https://doi.org/10.1121/1.5134465.

3. Collée A, Watelet JB, Vanmaele, Thielen JV, Clarys P. Longitudinal changes in hearing threshold levels for noise-exposed military personnel. Int Arch Occup Environ Health. 2019;92(2):219-26, https://doi.org/10.1007/s00420-018-1368-6.

4. Kelly AC, Boyd SM, Henehan GT, Chambers G. Occupational noise exposure of nightclub bar employees in Ireland. Noise Health. 2012;14(59):148-54, https://doi.org/10.4103/1463-1741. 99868.

5. Wolniakowska A, Zaborowski K, Dudarewicz A, PawlaczykŁuszczyńska M, Śliwińska-Kowalska M. [Assessment of temporary hearing changes related to work as a bartender]. Med Pr. 2019;70(1):17-25, https://doi.org/10.13075/mp.5893.00734.

6. Frederiksen TW, Ramlau-Hansen Ch, Stokholm ZA, Grynderup MB, Hansen AM, Kristiansen J, et al. Noise-induced hearing loss - A preventable disease? Results of a 10-year longitudinal study of workers exposed to occupational noise. Noise Health. 2017;19(87):103-11, https://doi.org/10.4103/nah.NAH_100_16.

7. Seixas NS, Neitzel R, Stover B, Sheppard L, Feeney P, Mills D, et al. 10-Year prospective study of noise exposure and hearing damage among construction workers. Occup Environ Med. 2012;69:643-50. 
8. Lin HW, Furman AC, Kujawa SG, Liberman MC. Primary neural degeneration in the guinea pig cochlea after reversible noise-induced threshold shift. J Assoc Res Otolaryngol. 2011;12(5):605-16, https://doi.org/10.1007/s10162-011$0277-0$.

9. Liberman MC, Kujawa.SG. Cochlear synaptopathy in acquired sensorineural hearing loss: Manifestations and mechanisms. Hear Res. 2017;349:138-47, https://doi.org/10.1016/ j.heares.2017.01.003.

10. Fernandez KA, Jeffers PW, Lall K, Liberman MC, Kujawa SG. Aging after noise exposure. Acceleration of cochlear synaptopathy in "recovered ears". J Neurosci. 2015;35(19):750920, https://doi.org/10.1523/JNEUROSCI.5138-14.2015.

11. Furman AC, Kujawa SG, Liberman MC. Noise-induced cochlear neuropathy is selective for fibers with low spontaneous rates. J Neurophysiol. 2013;110(3):577-86, https://doi. org/10.1152/jn.00164.2013.

12. Hind SE, Haines-Bazrafshan R, Benton CL, Brassington W, Towle B, Moore DR. Prevalence of clinical referrals having hearing thresholds within normal limits. Int J Audiol. 2011;50:708-16, https://doi.org/10.3109/14992027.2011.582049.

13. Liberman MCh, Epstein MJ, Cleveland SS, Wang H, Maison SF. Toward a differential diagnosis of hidden hearing loss in humans. PLoS One. 2016;12;11(9):e0162726, https:// doi.org/10.1371/journal.pone.0162726.

14. Valderrama JT, Beach EF, Yeend I, Sharma M, Van Dun B, Dillon $\mathrm{H}$. Effects of lifetime noise exposure on the middleage human auditory brainstem response, tinnitus an speechin-noise intelligibility. Hear Res. 2018;365:36-48, https://doi. org/10.1016/j.heares.2018.06.003.

15. Prendergast G, Guest H, Munro KJ, Kluk K, Léger A, Hall DA, et al. Effects of noise exposure on young adults with normal audiograms I: Electrophysiology. Hear Res. 2017;344:68-81,https://doi.org/10.1016/j.heares.2016.10.028.

16. Prendergast G, Couth S, Millman RE, Guest H, Kluk K, Munro KJ, et al. Effects of Age and Noise Exposure on Proxy Measures of Cochlear Synaptopathy. Trends Hearing. 2019;23: 1-16, https://doi.org/10.1177/2331216519877301.
17. Le TN, Straatman LV, Lea J, Westerberg B. Current insights in noise-induced hearing loss: a literature review of the underlying mechanism, pathophysiology, asymmetry and management options. J Otolaryng Head Neck Sur. 2017;46(1):4155, https://doi.org/10.1186/s40463-017-0219-x.

18. Dobie RA, Humes LE. Commentary on the regulatory implications of noise-induced cochlear neuropathy. Int J Audiol. 2017;56(Suppl 1):74-8, https://doi.org/10.1080/149920 27.2016.1255359.

19. Moshammer H, Kundi M, Wallner P, Herbst A, Feuerstein A, Hutter HP. Early prognosis of noise-induced hearing loss. Occup Environ Med. 2015;72(2):85-9, https://doi. org/10.1136/oemed-2014-102200.

20. Brungart DS, Barrett ME, Schurman J, Sheffield B, Ramos L, Martorana R, et al. Relationship Between Subjective Reports of Temporary Threshold Shift and the Prevalence of Hearing Problems in Military Personnel. Trends Hear. 2019;23:23 31216519872601, https://doi.org/10.1177/2331216519872601.

21. Verbeek JH, Kateman E, Morata TC, Dreschler WA, Mischke C. Interventions to prevent occupational noise-induced hearing loss. Cochrane Database Syst Rev. 2012 Oct 17;10: CD006396, https://doi.org/10.1002/14651858.CD006396.pub3.

22. McTague MF, Galusha D, Dixon-Ernst C, Kirsche SR, Slade MD, Cullen MR, et al. Impact of daily noise exposure monitoring on occupational noise exposures in manufacturing workers. Int J Audiol. 2013;52 Suppl 1:S3-8, https://doi. org/10.3109/14992027.2012.743047.

23. Mills JH, Gilbert RM, Adkins WY. Temporary threshold shifts in humans exposed to octave bands of noise for 16 to 24 hours. J Acoust Soc Am. 1979;65:1238-48.

24. Melnick W. Human temporary threshold shift (TTS) and damage risk. J Acoust Soc Am. 1991;90:147-54.

25. Macrae JH. Prediction of asymptotic threshold shift caused by hearing aid use. J Speech Hear Res. 1994;37:1450-8.

26. Dudarewicz A, Pawlaczyk-Łuszczyńska M, Śliwińska-Kowalska M, Katrakazas P, Pontoppidan NH, Koutsouris D. Predicting impact of loud incidents on individual hearing for public health policy in the framework of EVOTION. 
In: Euronoise 2018 Crete Conference and Conference Proceedings, 2018 May 27-31; Heraclion, Crete, Greece. Heraclion: I.A.C.M, F.O.R.T.H.; 2018. p. 375-80. Available from: http://www.euronoise2018.eu/docs/papers/65_Euronoise2018.pdf.

27. Heidari A, Moosav A, Yadegari F, Bakhshi E, Ahadi M. Effects of age on Speech-in-Noise identification: Subjective rating of hearing difficulties and encoding fundamental frequency in older adults. J Audiol Otol. 2018;22:134-9, https:// doi.org/10.7874/jao.2017.00304.

28. Skoe E, Camera S, Tufts J. Noise exposure may diminish the musicians advantage for perceiving speech in noise. Ear Hear. 2019;40(4):782-93, https://doi.org/10.1097/AUD.0000 000000000665 .

29. International Organization for Standardization. ISO 1999:2013. Acoustics - Estimation of noise-induced hearing loss [Internet]. Geneva: The Organization; 2013 [cited 2019 Dec 20]. Available from: https://www.iso.org/standard/45103.html.

30. Lie A, Skogstad M, Johannessen HA, Tynes T, Mehlum IS, Nordby KC, et al. Occupational noise exposure and hearing: a systematic review. Int Arch Occup Environ Health. 2016;89(3):351-72, https://doi.org/10.1007/s00420-0151083-5.

31. Pleban FT, Oketope O, Shrestha L. Occupational Styrene Exposure on Auditory Function Among Adults: A Systematic Review of Selected Workers. Saf Health Work. 2017;8(4): 329-36, https://doi.org/10.1016/j.shaw.2017.01.002.
32. Hormozi M, Ansari-Moghaddam A, Mirzaei R, Dehghan Haghighi J, Eftekharian F. The risk of hearing loss associated with occupational exposure to organic solvents mixture with and without concurrent noise exposure: A systematic review and meta-analysis. Int J Occup Med Environ Health. 2017;30(4):521-35, https://doi.org/10.13075/ijomeh.1896.01024.

33. Directive 2003/10/EC of the European Parliament and of the Council of 6 February 2003 on the minimum health and safety requirements regarding the exposure of workers to the risks arising from physical agents (noise) (Seventeenth individual Directive within the meaning of Article 16(1) of Directive 89/391/EEC). Off J Eur Union, L42/38, p. 38-44 (Feb 15, 2003).

34. Pawlaczyk-Luszczynska M, Dudarewicz A, Zamojska M, Sliwinska-Kowalska M. Self-Assessment of Hearing Status and Risk of Noise-Induced Hearing Loss in Workers in a Rolling Stock Plant. JOSE. 2012;18(2):279-96, https://doi.org/10.1080/ 10803548.2012.11076934.

35. González ER, Kosk-Bienko J, editors. Combined exposure to noise and ototoxic substances [Internet]. European Agency for Safety and Health at Work (EU-OSHA). Luxembourg: Office for Official Publications of the European Communities; 2009, https://doi.org/10.2802/16028.

36. Fuente A, Slade MD, Taylor T, Morata TC, Keith RW, Sparer J, et al. Peripheral and central auditory dysfunction induced by occupational exposure to organic solvents. J Occup Environ Med. 2009;51(10):1202-11, https://doi.org/10.1097/ JOM.0b013e3181bae17c.

This work is available in Open Access model and licensed under a Creative Commons Attribution-NonCommercial 3.0 Poland License - http://creativecommons.org/ licenses/by-nc/3.0/pl/deed.en. 